\title{
UTAH VARIETIES OF A ROSE ROOT GALL WASP (HYMENOP'TERA) ${ }^{1}$
}

By Allan R. Hubter.

\section{Diplolepis radicum var. utahensis (Bassett)}

Rhodites Utahensis Bassett, 1890, Trans. Amer. Ent. Soc., XVII, p. 62.

Diplolepis radicum utahensis Kinsey, 1922 (in part), Ind.

Univ. Studies, 53, p. 68.

Female.-Differs from the female of variety angustior in the following characters; Parapsidal grooves more gradually convergent toward and more separated at the scutellum; median groove distinctly but discontinuously indicated for one half the mesonotal length; anterior parallel lines not as distinct toward the pronotum; the smooth area on the scutellum is larger, more rugose, and connected to the mesonotum by a much wider isthmus; the transverse, rugose band across the mesopleura is considerably wider and less distinct in outline; the rufous area on the abdomen, dorso-basally, is larger and lighter; the areolet is a little smaller.

Male.-Differs from the male of variety angustior only in varietal characters as described for the female.

Gall.-Practically the same as the gall of angustior.

Range.-Utah: Thistle (Weld), Price (Kinsey). Probably occurs throughout the Colorado Plateau country of parts of Utah, Colorado, New Mexico, and Arizona.

Types.-Lost.

Diplolepis radicum var. angustior var. nov.

Diplolepis radicum utahensis Kinsey, 1922 (in part), Ind. Univ. Studies, 53, p. 68.

Female.-Differs from utahensis in the following characters: Parapsidal grooves make an abrupt curve in, and converge more closely at the scutellum; median groove is variable, from a mere indication at the scutellum to discontinuous indications for one-third of the mesonotal length, and is less distinct; an-

1 Contribution from the Zoological Laboratories of Indiana University No. 195 (Entomological No. 4). 
terior parallel lines more distinct toward the pronotum; the smooth area on the scutellum is smaller, more distinct in outline, not so rugose, and connected to the mesonotum by a narrower isthmus; the transverse, rugose band across the mesopleura is considerably narrower and more distinct in outline; the rufous area on the abdomen, dorso-basally, is smaller and darker; the areolet is a little larger.

Male.-Differs from the male of variety utahensis only in varietal characters as described for the female.

Gall.-Practically the same as the gall of utahensis.

Range.-Utah: Provo, Brigham (Kinsey). Probably confined to more northern Utah and adjacent Idaho.

Types.-A great many females, about forty galls. Holotype female, paratype females, males, and galls at The American Museum of Natural History; paratype adults and galls at the Museum of Comparative Zoology, the U. S. National Museum, the Philadelphia Academy, Stanford University, the California Academy, and the Kinsey collection. Labelled Provo, Utah; April 18, 1920; Kinsey collector.

The variety utahensis is found at Price, Utah, while variety angustior is found at Provo; the two localities are separated by only sixty miles, but Price is a thousand feet higher in elevation. The two varieties are so closely related that they have heretofore been considered the same; the relationship is so close that they are hardly separable on any one character, but they are easily distinguished by a combination of characters. The most distinctive characters are the transverse rugose band on the mesopleura, the size of the areolet, and the smooth area and isthmus on the scutellum.

It is interesting to note that all other Cynipidæ known from Utah have two very closely related varieties in a more northern and more southern faunal area; utahenesis has been the only ex ception, but now that angustior has been described, the rule holds without exception. Plana, another variety of the same species from southeastern Oregon is almost as closely related to utahensis and angustior.

Dr. Kinsey of the Zoology Department of Indiana University has supervised this study. 

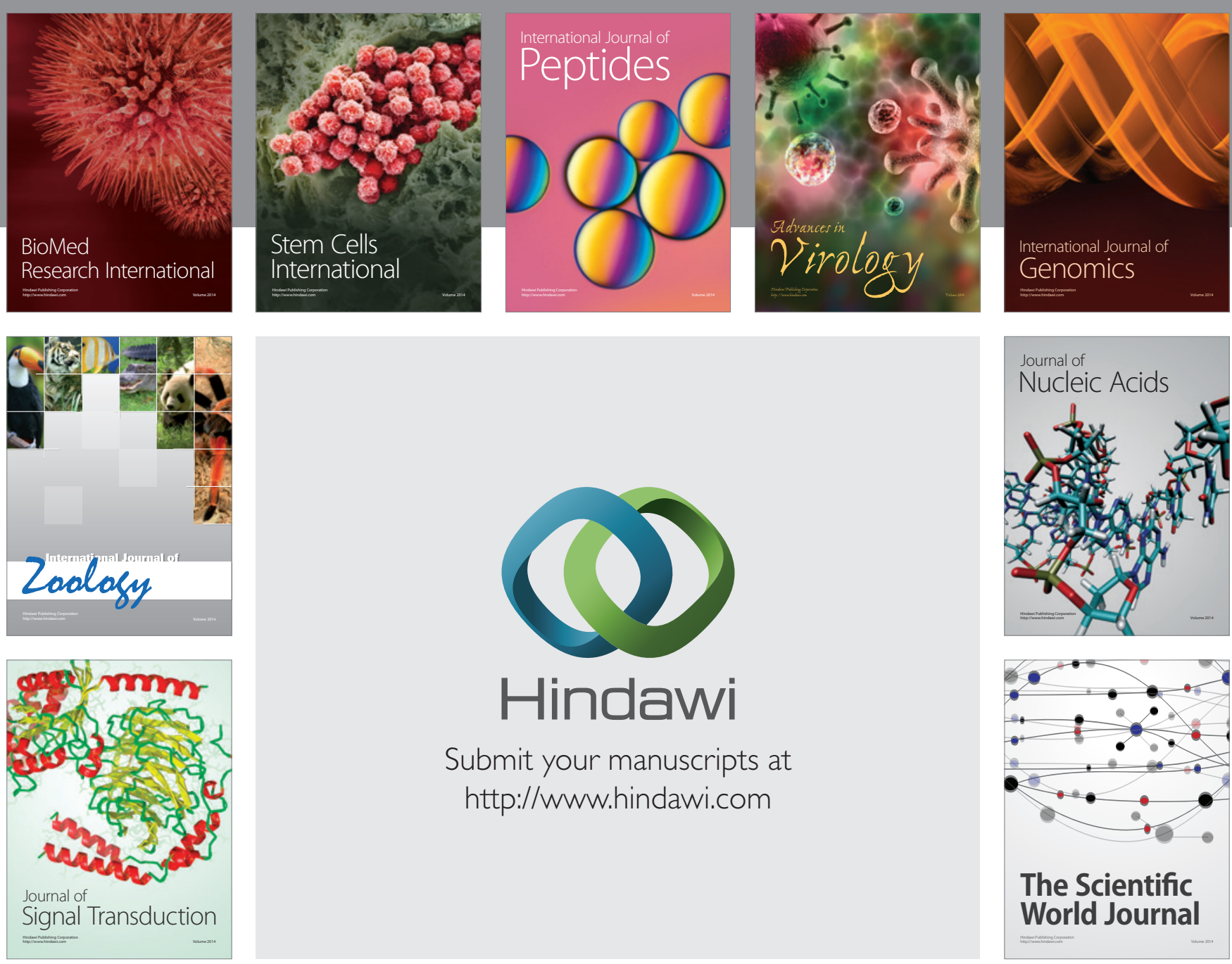

Submit your manuscripts at

http://www.hindawi.com
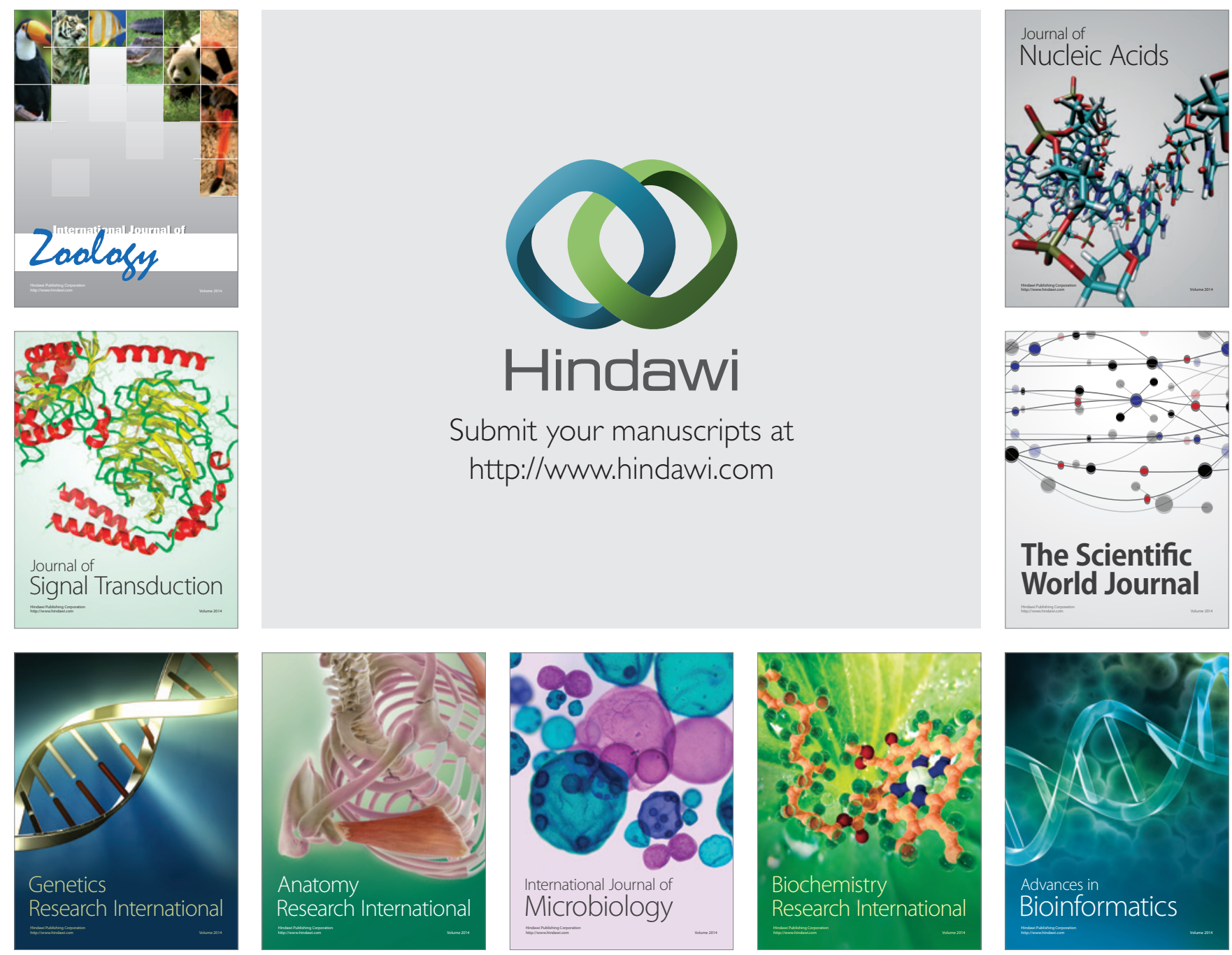

The Scientific World Journal
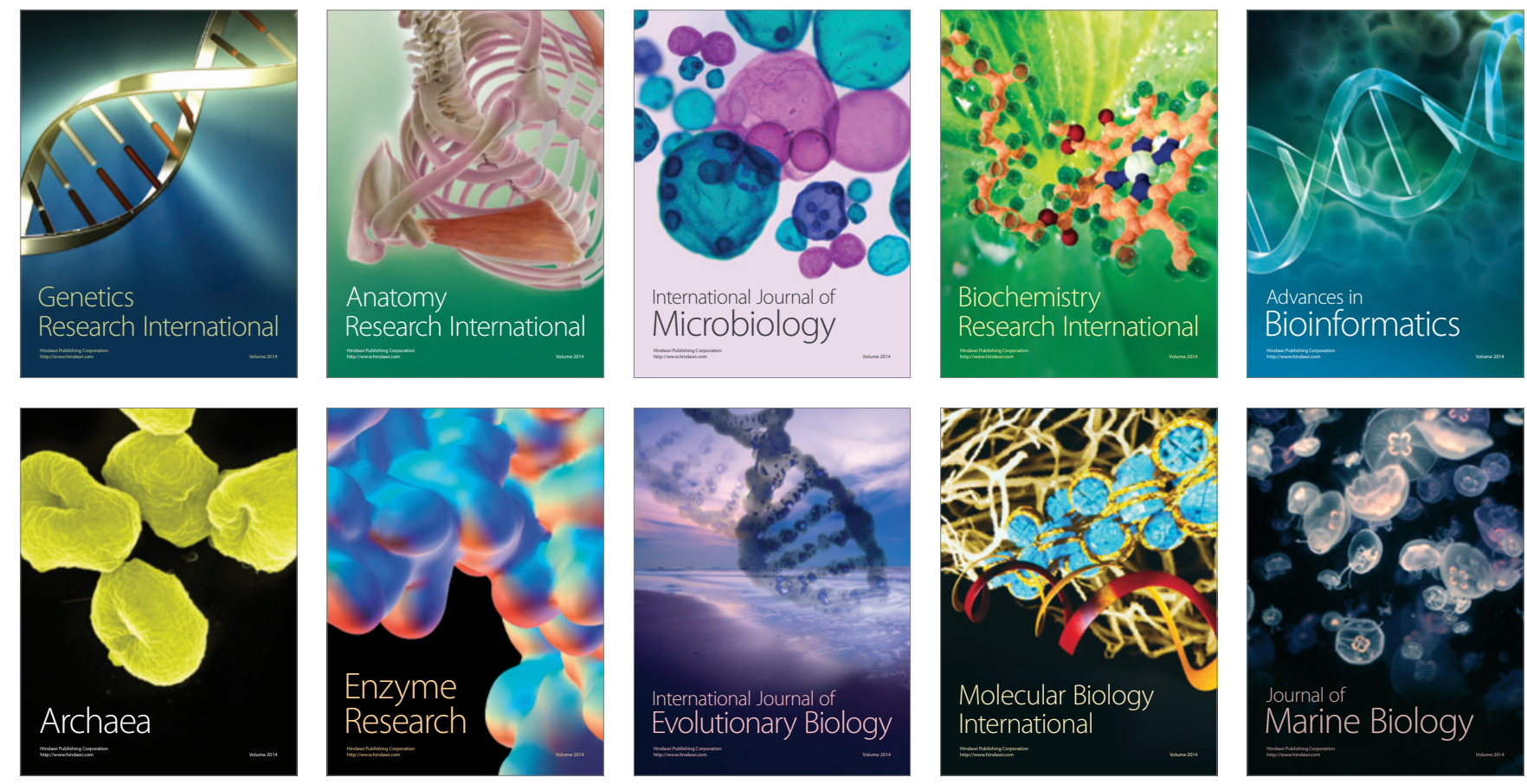